\title{
Parachute structure trisiloxane surfactant: synthesis and its use in reverse flotation of iron ore
}

\section{Zhiqiang Huang ( $\nabla$ zhiqiang@jxust.edu.cn )}

Jiangxi University of Science and Technology

Shiyong Zhang

Jiangxi University of Science and Technology

Vladimir E. Burov

Perm National Research Polytechnic University

Hongling Wang

Guangdong Institute of Resources Comprehensive Utilization

\section{Rukuan Liu}

Hunan Academy of Forestry

\section{Chen Cheng}

Jiangxi University of Science and Technology

\section{Shuyi Shuai}

Jiangxi University of Science and Technology

\section{Wenyuan Li}

Jiangxi University of Science and Technology

\section{Xinyang Yu}

Jiangxi University of Science and Technology

\section{Guichun He}

Jiangxi University of Science and Technology

Weng Fu

The University of Queensland

\section{Vladimir Z. Poilov}

Perm National Research Polytechnic University

\section{Article}

Keywords:

Posted Date: December 30th, 2021

DOI: https://doi.org/10.21203/rs.3.rs-1201700/v1 
License: (c) (i) This work is licensed under a Creative Commons Attribution 4.0 International License. Read Full License 


\section{Abstract}

No single element has exerted such a deep influence on social organization of mankind as iron. Magnetite is concentrated by froth flotation and used as a raw material to produce iron. However, the conventional surfactants used in the flotation process often lead to the weak collecting performance due to their analogous alkyl hydrophobic group. Here, we report a new trisiloxane surfactant $\mathrm{N}$-( $\beta$-aminoethyl)$y$-aminopropyltrisiloxane (AAT) in magnetite flotation, which was compared with the traditional collector dodecylamine (DA). The flotation test results showed that AAT had excellent collecting ability and selectivity for quartz against magnetite. Magnetite concentrate with TFe recovery of $84.79 \%$, TFe grade of $68.84 \%$ and $\mathrm{SiO}_{2}$ grade of $6.15 \%$ was obtained by using $150 \mathrm{~g} / \mathrm{t}$ AAT. Density functional theory calculations suggested reactive site of AAT was cationic $-\mathrm{CH}_{2} \mathrm{~N}^{+} \mathrm{H}_{3}$ group, and AAT showed a higher positive grouping Mulliken charge and chemical reactivity that may promote its flotation performance.

\section{Introduction}

Opening Mendeleev's periodic table of elements, there is no longer an element that is as important as iron for the past, present, and future destiny of mankind. Reviewing the history of human development, the use of iron has always played a role in promoting the change of human times and the transformation to modernization, whether as a tool for peaceful labor, the foundation of culture and industry, or as a weapon in wartime ${ }^{1-5}$. As the most important element in the nature around us, nowadays, the important role of iron in social economic development and scientific and technological progress will only increase and not decrease. Iron is the most widely used metal in the world, and its consumption accounts for about $95 \%$ of the total metal consumption. According to the latest research reports, research experts predict that the global consumption of iron will continue to grow with the development of global industrialization ${ }^{6,7}$. Therefore, how to improve iron production efficiently to adapt to industrial development is an urgent problem. Magnetite $\left(\mathrm{Fe}_{3} \mathrm{O}_{4}\right)$, the main resource of iron production, is commonly received from magnetite ore by a physical beneficiation method reverse froth flotation ${ }^{8,9}$. Furthermore, the key of reverse flotation is to selectively increase the floatability of quartz by adding collectors, and its specific principle is that the hydrophilic groups of collectors are adsorbed on the surface of quartz, while the hydrophobic groups enter into the bubble, thus forming hydrophobic quartz-bubbles ${ }^{10-12}$.

In recent years, various reverse flotation collectors of magnetite ore have been studied and applied ${ }^{13-15}$. Dodecylamine is commonly used industrially as a collector in the reverse flotation of silicate gangue from magnetite ore ${ }^{16}$. The mixture of sodium oleate and hexadecyl trimethyl ammonium bromide (molar ratio of $1: 2$ ) was first introduced in reverse flotation of magnetite ore at $\mathrm{pH} 5.5^{15}$. In addition, alkyl ether amines also have been studied as a collector for quartz in the reverse flotation of magnetite ore ${ }^{12,16}$. Seriously, the conventional magnetite reverse flotation collector mentioned above is a surfactant with an analogous and onefold alkyl hydrophobic groups, which often has problems such as low efficiency and large reagent consumption in the flotation process ${ }^{19-21}$. Thus, it is of great practical significance to study a new collector with high flotation efficiency to promote the industrial production of magnetite. 
Trisiloxane surfactant (MD'M) is a new style of organosilicone surfactant. In its structure, $M$ stands for trimethylsiloxane $\left(\mathrm{CH}_{3}\right)_{3} \mathrm{SiO}_{1 / 2}$, D' means $-\mathrm{O}_{1 / 2} \mathrm{Si}\left(\mathrm{CH}_{3}\right)(\mathrm{R}) \mathrm{O}_{1 / 2^{2}}$, as for $\mathrm{R}$, it's the hydrophilic group connected to silicon by a propyl spacer. Because of the following characters of MD'M trisiloxane - the bond of Si-O can be flattened on the surface of liquid, the low-energy methyl can be completely exposed to the air and distributed on the interface in a parachute structure, therefore, MD has the ability to abate the water surface tension to $\sim 21 \mathrm{mN} / \mathrm{m}$ with an efficient method ${ }^{22-24}$. Compared with the traditional surfactant containing alkyl hydrophobic group, trisiloxane surfactant has more excellent properties, such as a lower surface tension, better spreading and wettability, good heat resistance and foaming performance, besides, with no toxic and side effects ${ }^{25-27}$. Therefore, the trisiloxane surfactants supported some industires such as cosmetics, lubricants, pesticide additives, coatings and daily chemicals and so on for many years ${ }^{28,29}$.

To the best of our knowledge, trisiloxane surfactant has not been applied as collector for magnetite reverse flotation. It is worth paying attention to the flotation effect and mechanism of trisiloxane surfactant on quartz and magnetite. In this work, a new "parachute" structure of trisiloxane surfactant N( $\beta$-aminoethyl)-y-aminopropyltrisiloxane (AAT) was prepared. The reverse flotation ability of AAT on quartz and magnetite was compared with that of common collector dodecylamine (DA). The mechanism of trisiloxane surfactant AAT on quartz and magnetite was studied through the structure-adsorption relationships of collector by DFT, contact angle, zeta potential and FTIR spectroscopy. It has characteristic amphiphilic properties and an unusual "parachute" molecular structure with both organic and inorganic functions, bringing an immense potential in iron industry production. The present study showed that as a reverse flotation collector, trisiloxane surfactant AAT significantly improved the utilization of iron ore resources, because AAT had better flotation performance, chemical activity and higher positive grouping Mulliken charge of $-\mathrm{CH}_{2} \mathrm{~N}^{+} \mathrm{H}_{3}$ group than traditional alkyl surfactant DA (Fig. 1).

\section{Results}

\section{Synthesis and structure determination of AAT}

As shown in Fig. 2a, the designed trisiloxane collector (AAT) was prepared by a one-step reaction. Adding $\mathrm{N}$-( $\beta$-aminoethyl)- $\gamma$-aminopropyl methyl dimethoxy silane $(41.27 \mathrm{~g}, 0.2 \mathrm{~mol})$, hexamethylldisiloxane $(162.00 \mathrm{~g}, 1 \mathrm{~mol})$, and tetramethylammonium hydroxide $(1.00 \mathrm{~g}, 0.01 \mathrm{~mol})$ in a reactor, stirred and heated continuously for $3 \mathrm{~h}$ under a nitrogen atmosphere at $95^{\circ} \mathrm{C}$. Then the quaternary ammonium hydroxide was obtained from the reaction, to make it inactivate, keep the temperature at $135^{\circ} \mathrm{C}$ for $50 \mathrm{~min}$, after that the excessive hexmethyldisiloxane in the mixture would be extracted by distillation. Finally, $\mathrm{N}-(\beta-$ aminoethyl)-y-aminopropyltrisiloxane $(51.76 \mathrm{~g}, 0.161 \mathrm{~mol})$ was obtained from fraction-purification operation, in a yield of $80.52 \%$, which was a colorless liquid.

The NMR spectroscopy of AAT was showed in Supplementary Figs. $1 \mathrm{a}$ and $\mathrm{b} .{ }^{1} \mathrm{H}$ NMR $\left(\mathrm{d}_{6}\right.$-DMSO, 400 $\mathrm{MHz}, \delta): 0.03\left(\mathrm{~s}, 3 \mathrm{H},-\mathrm{SiCH}_{3}, 1-\mathrm{H}\right), 0.09\left(\mathrm{~s}, 18 \mathrm{H}, 2-\mathrm{Si}\left(\mathrm{CH}_{3}\right)_{3}, 2-\mathrm{H}\right), 0.50\left(\mathrm{t}, 2 \mathrm{H},-\mathrm{SiCH}_{2}-, 3-\mathrm{H}\right), 1.27(\mathrm{~m}$, 
$\left.2 \mathrm{H},-\mathrm{CH}_{2} \mathrm{CH}_{2} \mathrm{Si}-, 4-\mathrm{H}\right), 1.45\left(\mathrm{~m}, 3 \mathrm{H},-\mathrm{NH}+\mathbf{+}-\mathrm{NH}_{2}, 6,9-\mathrm{H}\right), 2.48\left(\mathrm{~m}, 4 \mathrm{H},-\mathrm{CH}_{2} \mathrm{NHCH}_{2}-\right.$, 5, 7- $\left.\mathrm{H}\right), 2.58(\mathrm{~m}$, $\left.2 \mathrm{H},-\mathrm{CH}_{2} \mathrm{NH}_{2}, 8-\mathrm{H}\right) .{ }^{13} \mathrm{C} \mathrm{NMR}\left(\mathrm{d}_{6}-\mathrm{DMSO}, 100 \mathrm{MHz}, \delta\right): 0.05\left(-\mathrm{Si}_{C_{3}}, \mathrm{a}-\mathrm{C}\right), 2.19\left(-\mathrm{Si}\left(\mathrm{CH}_{3}\right)_{3}, \mathrm{~b}-\mathrm{C}\right), 15.17(-$ $\left.\mathrm{SiCH}{ }_{2}^{-}, \mathrm{c}-\mathrm{C}\right)$, $23.71\left(-\mathrm{CH}_{2} \mathrm{CH}_{2} \mathrm{Si}-, \mathrm{d}-\mathrm{C}\right), 42.04\left(-\mathrm{CH}_{2} \mathrm{NH}_{2}, \mathrm{~g}-\mathrm{C}\right), 52.79\left(-\mathrm{CH}_{2} \mathrm{CH}_{2} \mathrm{NH}_{2}, \mathrm{f}-\mathrm{C}\right), 53.05\left(-\mathrm{CH}_{2}\right.$, eC). Supplementary Figs. 1c presented FTIR spectra of AAT, FTIR (KBr): $3288(\mathrm{UC}-\mathrm{N}), \mathrm{U} 2927\left(\mathrm{UCH}_{3}, \mathrm{UCH}_{2}\right)$, u $2879\left(\mathrm{uCH}_{3}, \mathrm{UCH}_{2}\right), 2817\left(\mathrm{uCH}_{3}, \mathrm{UCH}_{2}\right), 1260(\mathrm{USi}-\mathrm{C}), 1592\left(\mathrm{UNH}_{2}, \mathrm{UNH}\right), 1465\left(\mathrm{uCH}_{3}, \mathrm{UCH}_{2}\right), 1302(\mathrm{UC}-$ N), 1080 (uSi-O-Si), $847(\mathrm{USi}-0) \mathrm{cm}^{-1}$.

\section{Micro-flotation tests}

Fig. $2 \mathrm{c}$ and $\mathrm{d}$ reflected the influence of the dosage of collector in quartz and magnetite flotation. The quartz recovery first increased with the increase of collector dosage, and then stabilized after reaching the maximum. AAT reached the maximum quartz recovery of $99 \%$ when the dosage was $5 \times 10^{-5} \mathrm{~mol} / \mathrm{L}$, which was $1 / 3$ of the dosage of DA to achieve the maximum quartz recovery of $95 \%$. At the same time, the magnetite recovery did not change with the increase of collector dosage (in Fig. 2d and Supplementary Video 1), showing excellent selectivity of AAT and DA for the flotation of quartz and magnetite. Many studies have shown that the close arrangements of $-\mathrm{CH}_{3}$ groups and the stretchy $\mathrm{Si}-\mathrm{O}$ chain increase the hydrophobicity of the mineral surface, making mineral particles easier to accumulate at the gas-liquid interface, compared with a straight alkyl chain ${ }^{30,31}$. Lower surface tension is beneficial to the formation of small foams with better mineralization effect and fastness ${ }^{32,33}$. In addition, trisiloxane collector has better ability to prevent bubble coalesce and achieve foam stability than traditional collector ${ }^{27,34}$.

Fig. 2e revealed the influence of $\mathrm{pH}$ on quartz and magnetite recovery with $5 \times 10^{-5} \mathrm{~mol} / \mathrm{L}$ collector. When the $\mathrm{pH}$ value increased from 2 to 6 , the quartz recoveries both with AAT and DA collectors increased rapidly, and the quartz recovery with AAT collector reached at maximum of $99.5 \%$, while only $60 \%$ with DA collector at $\mathrm{pH} 6$. However, when $\mathrm{pH}$ value increases from 6 to 12, quartz recoveries decreased rapidly with DA collector, whereas that with AAT collector decreased only a little. As we can see, the quartz recovery curve of AAT was consistently above that of DA throughout the $\mathrm{pH}$ experiment. Thus, trisiloxane surfactants AAT had better collecting ability and $\mathrm{pH}$ adaptability than traditional surfactant DA.

\section{Bench-scale flotation tests}

In order to compare the influence of AAT and DA collector in magnetite ore flotation, the tests were carried out with $150 \mathrm{~g} / \mathrm{t}$ AAT or $300 \mathrm{~g} / \mathrm{t} \mathrm{DA}$ at optimum pH 6. As presented in Fig. 2f, the TFe grade and $\mathrm{SiO}_{2}$ grade of magnetite concentrate with AAT collector were $68.84 \%$ and $6.15 \%$ respectively, reaching the standard of $\mathrm{C}_{68}$ ( $\mathrm{TFe}$ grade $\geq 68.0 \%$ and $\mathrm{SiO}_{2}$ grade $\left.\leq 6.5 \%\right)^{35}$, indicating that magnetite had been recovered greatly in magnetite concentrate. Unfortunately, $\mathrm{DA}$, which received a magnetite concentrate of $\mathrm{C}_{66}$ (TFe grade $66.0 \% \sim 67.0 \%$ and $\mathrm{SiO}_{2}$ grade $\leq 7.0 \%$ ) level with $66.35 \%$ TFe grade and $6.78 \% \mathrm{SiO}_{2}$ grade, showed a lower capability. Meanwhile, the recovery of TFe obtained by $150 \mathrm{~g} / \mathrm{t}$ AAT was $11.53 \%$ higher than that of using $300 \mathrm{~g} / \mathrm{t}$ DA as collector. Therefore, the results showed that AAT could achieve effective separation of magnetite and quartz to obtain high quality magnetite concentrate. 


\section{Contact angle measurement}

Fig. 3a showed the contact angles of two minerals treated with different collector concentrations. The initial contact angles of them (collector concentration was 0 ) were $18.5^{\circ}$ and $34.6^{\circ}$, respectively, which were similar to the reported values in related literature ${ }^{36,37}$. As the AAT/DA concentration increased from low, the contact angle of quartz also increased. The reason was that the hydrophilic group in the collector molecule was adsorbed on the quartz surface, and another hydrophobic group was extended in the water, which enhanced the hydrophobicity of the quartz surface and increased the contact angle. Novertheless, when the concentration was $1 \times 10^{-5} \mathrm{~mol} / \mathrm{L}$, the contact angle of quartz with AAT was $73.1^{\circ}$, while the contact angle with DA $65.1^{\circ}$. In addition, the contact angles of magnetite varied little with the change of collector concentration, indicating that AAT collectors had little effect on the hydrophobicity of magnetite. This result showed that the AAT collector could effectively enhance the hydrophobicity of the quartz surface, which was consistent with the flotation experiment results.

\section{FTIR spectroscopy analysis}

In order to clarify the adsorption mechanism of AAT on the mineral surface, FTIR spectroscopy of two minerals before and after treatment with AAT collector were investigated. As shown in Fig. 3b and c, the infrared spectrum of pure quartz and magnetite were basically consistent with other literature ${ }^{38,39}$. In Fig. 3b, after treatment with trisiloxane collector AAT, the new peaks at $2926 \mathrm{~cm}^{-1}$ and $2855 \mathrm{~cm}^{-1}$ appeared on the quartz surface, which were attributed to the stretching vibration peak of $-\mathrm{CH}_{2}$ and $\mathrm{CH}_{3}$ of AAT, showing that AAT has adsorption on the quartz surface. At the same time, it was speculated that no new compounds were formed between AAT and quartz due to the absence of other peaks. In Fig. 3c, there was no change in the infrared spectrum of magnetite after AAT treatment, indicating that AAT was not adsorbed on magnetite, which was consistent with the flotation experiment results.

\section{Zeta potential measurement}

Electromotive force measurement is an important means to explore the changes of mineral surface electrodynamic properties, explain the adsorption phenomenon and analyze the adsorption mechanism ${ }^{40,41}$. As shown in Fig. $3 \mathrm{~d}$ and e, to further understand the adsorption mechanism of AAT on mineral surface, the changes of the zeta-potential of two minerals with $\mathrm{pH}$ value were measured in the presence and absence $5 \times 10^{-5} \mathrm{~mol} / \mathrm{L}$ AAT/DA. In the test results, the zero electric points of quartz and magnetite were 2.63 and 5.66 , respectively, which were consistent with relevant research results ${ }^{42-44}$. In Fig. 3d, the zeta potential of the quartz without collector was negative in the $\mathrm{pH}$ range of 4-12, indicating that the quartz surface was negatively charged. However, after interacting with the collectors, the zeta potential of the quartz with AAT and DA moved in a positive direction, suggesting that $\mathrm{AAT}^{+}$and $\mathrm{DA}^{+}$were adsorbed on the quartz surface by electrostatic force. In addition, the zeta potential of quartz with AAT was much larger than that with DA, indicating that the adsorption of AAT was much stronger than that of DA, which was consistent with the flotation experiment results. For magnetite (Fig. 3e), the presence of AAT or DA had little effect on the zeta potential of magnetite, indicating that the two collectors did not 
adsorb on magnetite. The zeta potential measurement results indicated that AAT the main interaction between AAT and quartz was electrostatic attraction, which was verified with the FTIR spectroscopy analysis.

\section{DFT calculation}

The space and electronic structure of the molecule are important factors that determine whether the surfactant is effective as a collector. Recently, density functional theory (DFT) is an effective and convenient quantum mechanical method to explain the interaction mechanism between minerals and collectors ${ }^{45,47}$. The optimized geometric structures of the $\mathrm{AAT}^{+}$and $\mathrm{DA}^{+}$were shown in Fig. $4 \mathrm{a}$. The eigenvalues of frontier orbits and the selected atomic charges were calculated and displayed in Table 1.

Molecular electrostatic potential (MEP) is usually used to reveal the electron density of the target molecule, and the MEP map is a very meaningful descriptor for predicting the nucleophilic and electrophilic active sites in the reaction ${ }^{12,48}$. Generally, the red area represents the most negatively charged part of the molecule, which is also the active part of electrophilic attack, while the blue area corresponds to the most positively charged part of nucleophilic attack. The MEP map of AAT and DA were shown in Fig. 4b, showing that two blue regions appear on the $-\mathrm{N}^{+} \mathrm{H}_{3}$ group, but the blue degree of AAT was deeper than that of DA. Practically, the $-\mathrm{N}^{+} \mathrm{H}_{3}$ groups in AAT and DA could generate electrostatic attraction with negative charge sites on the mineral surface. Here, the natural charge was calculated to discuss the net atomic charge of the collectors, as shown in Table 1. For two collectors, the positive charge was mainly concentrated on the $\mathrm{H}$ atoms connecting $\mathrm{N}_{13}$ atoms. Cationic groups $-\mathrm{CH}_{2} \mathrm{~N}^{+} \mathrm{H}_{3}$ was the main active group of AAT and DA molecules. However, the Mulliken atomic charges of the cationic groups $-\mathrm{CH}_{2} \mathrm{~N}^{+} \mathrm{H}_{3}$ from $\mathrm{AAT}^{+}$and $\mathrm{DA}^{+}$were 0.355 and 0.213 , respectively, showing that $\mathrm{AAT}^{+}$and $\mathrm{DA}^{+}$can generate electrostatic attraction with negative charge sites on the quartz surface, while the electrostatic attraction between AAT and quartz was stronger than that of DA, which was consistent with the zeta potential measurement (Fig. 3d), flotation experiment and contact angle measurement results.

Frontier molecular orbital (FMO) theory is a famous molecular orbital theory, which is a widely used method to evaluate the properties of chemical reactions ${ }^{49,50}$. The highest occupied molecular orbital (HOMO) is mainly composed of Px or Pz orbitals of carbon atoms, and the lowest unoccupied molecular orbital (LUMO) is mainly composed of S-orbitals of $\mathrm{N}, \mathrm{C}$ and $\mathrm{H}$ atoms, representing the properties of electron donor and acceptor, respectively. It can be seen from Table 1 that the HOMO values of $\mathrm{AAT}^{+}$and $\mathrm{DA}^{+}$were very low, indicating that their ability to provide electrons were very weak. This was because the valence states of these carbon atoms had been completely filled and there was no opportunity to provide p-orbital electrons to other atoms. The LUMO values of $\mathrm{AAT}^{+}$and $\mathrm{DA}^{+}$were also low, indicating that LUMO could not accept feedback electrons to form $\pi$-bonds. Thus, it was difficult for $\mathrm{AAT}^{+}$and $\mathrm{DA}^{+}$to form covalent bonds with iron on magnetite surface and silicon on quartz surface, which was consistent with the above-mentioned FTIR spectroscopy analysis (Fig. 3b). In Fig. 4c, the LUMO of the two collectors 
was mainly concentrated on $-\mathrm{N}^{+} \mathrm{H}_{3}$ group, indicating that $-\mathrm{N}^{+} \mathrm{H}_{3}$ group played a leading role in the electrostatic attraction between collectors and quartz surface. In addition, the energy gap between HOMO and LUMO could be used as an indicator of the stability of organic compounds. The smaller the energy gap, the lower the molecular stability and the higher the chemical reactivity. From Table 1, The order of energy gap $\triangle \mathrm{E}_{\text {LUMO-HOMO }}$ was $\mathrm{AAT}<\mathrm{DA}$, indicating that the chemical reaction activity of AAT was stronger than DA.

The above results showed the behavior of AAT and DA at the molecular level, verified the adsorption mechanism between AAT and mineral surface, and further proved that the active center of $\mathrm{AAT}^{+}$was mainly concentrated in the $-\mathrm{N}^{+} \mathrm{H}_{3}$ group, and comparing with traditional alkyl surfactants, trisiloxane surfactant showed a higher positive grouping Mulliken charge and chemical reactivity that might improve its flotation properties.

Table 1 The HOMO and LUMO values and the selected Mulliken charges of $\mathrm{AAT}^{+}$and $\mathrm{DA}^{+}$

\begin{tabular}{lllll}
\hline Collector & \multicolumn{2}{l}{ Eigenvalue/a.u } & Mulliken charge/electron & Group \\
\cline { 2 - 5 } & HOMO & LUMO & Atomic charge & \\
\hline AAT $^{+}$ & -0.334922 & -0.180567 & ${ }^{13} \mathrm{~N}:-0.751,{ }^{52} \mathrm{H}: 0.282,{ }^{53} \mathrm{H}: 0.299,{ }^{54} \mathrm{H}: 0.283,{ }^{51} \mathrm{H}: 0.213$ & $-\mathrm{CH}_{2} \mathrm{~N}^{+} \mathrm{H}_{3}: 0.355$ \\
\hline $\mathrm{DA}^{+}$ & -0.363816 & -0.158284 & ${ }^{13} \mathrm{~N}:-0.711,{ }^{39} \mathrm{H}: 0.282,{ }^{40} \mathrm{H}: 0.278,{ }^{41} \mathrm{H}: 0.183,{ }^{37} \mathrm{H}: 0.191$ & $-\mathrm{CH}_{2} \mathrm{~N}^{+} \mathrm{H}_{3}: 0.213$
\end{tabular}

\section{Economic estimation}

Economic estimation was used to compare the economic value of the new collector AAT with the traditional collector DA. Supplementary Table 2 displayed the industrial prices of agents. The market price of AAT was estimated based on its $80.52 \%$ yield and feedstock costs accounting for approximately $80 \%$ of the total cost.

Price of AAT

$=[(1 / 322.24) / 80.52 \% \times 206.36 \times 4,010+(1 / 322.24) / 80.52 \% \times 162.38 \times 5,500] / 80 \%$

$=8,289.06 \mathrm{USD} / \mathrm{t}$

Cost of AAT

$=150 \mathrm{~g} / \mathrm{t} \times 10,000 \mathrm{t} / \mathrm{d} \times 330 \mathrm{~d} \times 8,289.06 \mathrm{USD} / \mathrm{t}$

$=4,103,083.98$ USD

Cost of DA 
According to the actual mine results, the TFe recovery with AAT and

DA collectors were reached $84.79 \%$ and $73.26 \%$, respectively. The current price of magnetite concentrates of $\mathrm{C}_{68}$ and $\mathrm{C}_{66}$ are about 135 and $100 \mathrm{USD} / \mathrm{t}$, respectively. Based on the above estimates, the retained profits could increase by approximately $94,877,527.84$ USD every year. Thus, it is possible that the expansion of AAT to global magnetite mines will bring huge economic benefits.

\section{Profit of TFe}

$=[(10,000 \mathrm{t} / \mathrm{d} \times 330 \mathrm{~d} \times 51.42 \% \times 84.79 \%) / 68.84 \%] \times 135 \mathrm{USD} / \mathrm{t}-[(10,000 \mathrm{t} / \mathrm{d} \times 330 \mathrm{~d} \times 51.42 \%$ $\times 73.26 \%) / 66.36 \%] \times 100 \mathrm{USD} / \mathrm{t}$

$=94,822,611.82$ USD

Retained profits

$=94,822,611.82+(4,158,000.00-4,103,083.98)$ USD

$=94,877,527.84$ USD

\section{Conclusions}

Herein, a novel trisiloxane collector $\mathrm{N}$-( $\beta$-aminoethyl)-y-aminopropyltrisiloxane (AAT) was synthesized, characterized and first applied as a superior collector for the reverse flotation of magnetite ore. The flotation performance of AAT and the conventional collector dodecylamine (DA) for pure quartz, magnetite and magnetite ore were studied by both micro-flotation tests and bench-scale flotation tests. Flotation results show that at the optimal pH $6,5 \times 10^{-5} \mathrm{~mol} / \mathrm{L}$ AAT could obtain the highest quartz recovery of $99 \%$, amount of which was $1 / 3$ of the optimal dosage of DA leading to a higher quality magnetite concentrate $\left(\mathrm{C}_{68}\right.$ level $)$ by $150 \mathrm{~g} / \mathrm{t}$ AAT. The adsorption mechanism shows that AAT could be strongly adsorbed on quartz surface to greatly improve the hydrophobicity of quartz surface, and had little effect on the hydrophobicity of magnetite. In addition, AAT was electrostatic adsorbed on the quartz surface, rather than on magnetite surface since cationic groups $-\mathrm{CH}_{2} \mathrm{~N}^{+} \mathrm{H}_{3}$ from $A A T^{+}$is more positive and thus leads to a stronger electrostatic attraction with negative charge sites on the quartz surface. Economic estimation results further indicated that the use of AAT as a collector in a medium-sized iron ore plant could add significant economic profits. Consequently, the molecular design of "parachute" structure of trisiloxane surfactant AAT is a new and excellent collector to satisfy the imperious demands of improving property and reducing chemical depletion in practical industrial application, which has great theoretical and practical significance for the sustainable production of iron ores. 


\section{References}

1. Feldman', M., Master, D. M., Bianco', R. A., Burril, M., Stockhammer, P. W., Mittnik, A., Aja, A. J., Jeong, C. \& J. Krausel. Ancient DNA sheds light on the genetic origins of early Iron Age Philistines. Sci. Adv. 5, eaax0061 (2019).

2. Schillerl, M., Bizzarro, M. \& Siebert, J. Iron isotope evidence for very rapid accretion and differentiation of the proto-Earth. Sci. Adv. 6, eaay7604 (2020).

3. Kuntail, J., Jain, Y. M., Shukla, M. \& Sinha, I. Adsorption mechanism of phenol, p-chlorophenol, and pnitrophenol on magnetite surface: A molecular dynamics study. J. Mol. Liq. 288, 111053 (2019).

4. Casado, S., Laguna, M., Pacheco, J. \& Puche, J. C. Grouping products for the optimization of production processes: A case in the steel manufacturing industry. Eu.r J. Oper. Res. 286, 190-202 (2020).

5. Ma, N. \& Sammon, W. J. Enhancement of in-plant recycling of integrated steel mill offgas solid wastes by reallocating crucial zinc-bearing materials. J. Cleaner. Prod. 251, 119783 (2020).

6. Liu, Y., Li, H., Huang, S., An, H. \& Santagata, R. S. Ulgiati, Environmental and Economic-related impact assessment of iron and steel production. A call for shared responsibility in global trade. $J$ Cleaner Prod. 269,122239 (2020).

7. Nezamoleslami, R. \& Hosseinian, S. M. An improved water footprint model of steel production concerning virtual water of personnel: The case of Iran. J. Environ. Manage. 260, 110065 (2020).

8. Weng, X., Mei, G., Zhao, T. \& Zhu, Y. Utilization of novel ester-containing quaternary ammonium surfactant as cationic collector for iron ore flotation. Sep. Purif. Technol. 103, 187-194 (2013).

9. Zhu, Z., Yin, W., Han, H., Cao, S., Yang, B. \& Wang, D. Investigation on the influence of surface roughness on magnetite flotation from the view of both particle-particle and bubble-particle interactions. Colloid. Surfaces. A. 595, 124681 (2020).

10. Stinn, \& C. Allanore, A. Selective sulfidation of metal compounds. Nature. (2021). https://doi.org/10.1038/s41586-021-04321-5

11. Liao, Y., Ma, Z. \& Cao, Y. Improving reverse flotation of magnetite ore using pulse magnetic field. Miner. Eng. 138, 108-111 (2019).

12. Lu, Y., Wang, S. \& Zhong, H. Study on the role of a hydroxamic acid derivative in wolframite flotation: Selective separation and adsorption mechanism. Appl. Surf. Sci. 550, 149223 (2021).

13. Sahoo, H., Kar, B., Rath, S. S., Rao, D. S. \& Da, B.Processing of banded magnetit quartzite (BMQ) ore using flotation techniques. Powder. Technol. 256, 285-292 (2014). 
14. Ren, L., Qiu, H., Zhang, Y., Nguyen, A. V., Zhang, M., Wei, P. \& Long, Q. Effects of alkyl ether amine and calcium ions on fine quartz flotation and its guidance for upgrading vanadium from stone coal. Powder. Technol. 338, 180-189 (2018).

15. Qiao, X., Liu, A., Li, Z., Fan, J., Luo, C., Fan, P., Liu, Y. \& Fan, M. A novel miscible collector DDA-2octanol-kerosene: Properties and flotation performance. Miner. Eng. 156, 106475 (2020).

16. López-Valdivieso, A., Corona-Arroyo, M.A., Encinas-Oropesa, A., García-Martínez, H.A., Aquino-Rosalío, C.E. \& Nahmad-Molinari. Y. Inhibiting the amine flotation of magnetite through aggregation with uniform low magnetic fields and no chemical depressants. Miner. Eng. 119, 130-136 (2018).

17. Yang, Z., Teng, Q., Liu, J., Yang, W., Hu, D. \& Liu, S. Use of NaOL and CTAB mixture as collector in selective flotation separation of enstatite and magnetite. Colloid. Surfaces. A. 570, 484-486 (2019).

18. Huang, Z., Cheng, C., Li, K., Zhang, S., Zhou, J., Luo, W., Liu, Z., Qin, W., Wang, H., Hu, Y., He, G., Yu, X., Qiu, T. \& Fu, W. Reverse flotation separation of quartz from phosphorite ore at low temperatures by using an emerging Gemini surfactant as the collector. Sep. Purif. Technol. 246, 116923 (2020).

19. Brezáni, I., Škvarla, J. \& Sisol, M. Reverse froth flotation of magnesite ore by using (12-4-12) cationic Gemini surfactant. Miner. Eng. 110, 65-68 (2017).

20. Cheng, C., Huang, Z., Zhang, R., Zhou, J., Liu, Z., Zhong, H., Wang, H., Kang, Z., He, G., Yu, X., Ren, Z., Qiu, T., Hu, Y. \& Fu, W. Synthesis of an emerging morpholine-typed Gemini surfactant and its application in reverse flotation carnallite ore for production of potash fertilizer at low temperature. $J$ Cleaner Prod. 261, 121121 (2020).

21. Huang, Z., Zhang, S., Zhang, F., Wang, H., Zhou, J., Yu, X., Liu, R., Cheng, C., Liu, Z., Guo, Z., He, G., Ai, G. \& Fu, W. Evaluation of a novel morpholine-typed Gemini surfactant as the collector for the reverse flotation separation of halite from carnallite ore. J Mol Liq. 313, 113506 (2020).

22. Michel, A., Brauch, H., Worch, E. \& Lange, F. T. Homologue specific analysis of a polyether trisiloxane surfactant in German surface waters and study on its hydrolysis. Environ. Pollut. 196, 126-135 (2014).

23. Fang, L., Tan, J., Zheng, Y., Yang, G., Yu, J. \& Feng, S. Synthesis, aggregation behavior of novel cationic silicone surfactants in aqueous solution and their application in metal extraction. J. Mol. Liq. 231, 134-141 (2017).

24. Baratella, V. \& Trinchera, A. Organosilicone surfactants as innovative irrigation adjuvants: Can they improve water use efficiency and nutrient uptake in crop production? Agr. Water. Manage. 204, 149-161 (2018).

25. Deng, R., Zuo, W., Ku, J., Yang, Z. \& Hu, Y. Synthesis of a cationic organic silicone surfactant and its application in the flotation of smithsonite. In.t J. Miner. Process. 167, 113-121 (2017). 
26. Song, M., Ju, J., Luo, S., Han, Y., Dong, Z., Wang, Y., Gu, Z., Zhang, L., Hao, R. \& Jiang, L. Controlling liquid splash on superhydrophobic surfaces by a vesicle surfactant. Sci. Adv. 3, e1602188 (2017).

27. Tan, J., He, Z., Miao, Y. \& Lin, M. Synthesis and surface properties of polyether-based silicone surfactants with different siloxane groups. J. Surfactants. Deterg. 22, 875-883 (2019).

28. Tong, L., Yang, Y., Luan, X., Shen, J. \& Xin, X. Supramolecular hydrogels facilitated by a-cyclodextrin and silicone surfactants and their use for drug release. Colloid. Surfaces. A. 522, 470-476 (2017).

29. Zhao, M., Zhou, H., Chen, L., Hao, L., Chen, H. \& Zhou, X. Carboxymethyl chitosan grafted trisiloxane surfactant nanoparticles with $\mathrm{pH}$ sensitivity for sustained release of pesticide. Carbohyd. Polym. 243, 116433 (2020).

30. Peng, Z., Wu, Qi., Cai, T., Gao, H. \& Chen, K. Syntheses and properties of hydrolysis resistant twin-tail trisiloxane surfactants. Colloid. Surface. A. 342, 127-131 (2009).

31. Cao, C., Zhang, L., Zhang, X. \& Du, F. Effect of gum arabic on the surface tension and surface dilational rheology of trisiloxane surfactant. Food. Hydrocolloid. 30, 456-462 (2013).

32. Srdjan, M. B. Handbook of flotation reagents: chemistry, theory and practice: flotation of sulfde ores. Elsevier Science \& Technology Books. (2007).

33. Sharma, R., Kamal, A., Abdinejad, M., Mahajan, R. K. \& Kraatz, H. B. Advances in the synthesis, molecular architectures and potential applications of gemini surfactants. Adv. Colloid. Interface. Sci. 248, 35-68 (2017).

34. Sastry, N. V., Punjabi, S. H. \& Ravalji, I. R. Effect of t-octylphenoxylpolyethoxyethanol (TX-100) on the dilute aqueous solutionphase diagrams, surface activity and micellization behavior of non-ionic silicone surfactants (SS) in aqueous media. J. Mol. Liq. 177, 215-224 (2013).

35. GT/B 36704-2018, Iron ore concentrate. Beijing: China Standard Press (2018) (in Chinese).

36. Silva, K., Filippov, L. O., Piçarra, A., Flilippova, I. V., Lim, N., Skliar, A., Faustino, L. \& Filho, L. L. New perspectives in iron ore flotation: Use of collector reagents without depressants in reverse cationic flotation of quartz. Miner. Eng. 170, 107004 (2021).

37. Zhu, Z., Yin, W., Han, H., Cao, S., Yang, B. \& Wang, D. Investigation on the influence of surface roughness on magnetite flotation from the view of both particle-particle and bubble-particle interactions. Colloid. Surface. A. 595, 124681 (2020).

38. Ren, L., Zhang, Y., Bian, Y., Liu, X. \& Liu, C. Flotation behavior and separation mechanism of quartz and iron minerals in alpha-bromolauric acid reverse flotation system. Physicochem. Probl. Mi. 54, 992-1003 (2018). 
39. Yang, Z., Teng, Q., Liu, J., Yang, W., Hua, D. \& Liu, S. Use of NaOL and CTAB mixture as collector in selective flotation separation of enstatite and magnetite. Colloid. Surface. A. 570, 481-486 (2018).

40. Sahoo, H., Rath, S. K., Jena, S. S., Mishra, B. K. \& Das, B. Aliquat-336 as a novel collector for quartz flotation. Adv Powder. Technol. 26, 511-518 (2015).

41. Huang, Z., Shuai, S., Wang, H., Liu, R., Zhang, S., Cheng, C., Hu, Y., Yu, X., He, G. \& Fu. W. Froth flotation separation of lepidolite ore using a new Gemini surfactant as the flotation collector. Sep. Purif. Technol. doi: https://doi.org/10.1016/j.seppur.2021.119122.

42. Liu, C., Zhu, G., Song, S. \& Li, H. Flotation separation of smithsonite from quartz using calcium lignosulphonate as a depressant and sodium oleate as a collector. Miner. Eng. 131, 385-391 (2019).

43. Teng, Q. \& Wang, H. Effect of silicate bacteria on quartz flotation separation. Sep. Sci. Technol. 56, 982-990 (2019).

44. Liu, W., Liu, W., Wang, B., Duan, H., Peng, X., Chen, X. \& Zhao, Q. Novel hydroxy polyamine surfactant $\mathrm{N}$-(2-hydroxyethyl)-N-dodecylethanediamine: Its synthesis and flotation performance study to quartz. Miner. Eng. 142, 105894 (2019).

45. Gutiérrez, E., Rodríguez, J., Cruz-Borbolla, J., Alvarado-Rodríguez, J. \& Thangarasu, P. Development of a predictive model for corrosion inhibition of carbon steel by imidazole and benzimidazole derivatives. Corros. Sci. 108, 23-35 (2016).

46. Xu, B., Ji, Y., Zhang, X., Jin, X., Yang, W. \& Chen, Y. Experimental and theoretical studies on the corrosion inhibition performance of 4-amino-N,N-di-(2-pyridylmethyl)-aniline on mild steel in hydrochloric acid. RSC. Adv. 5, 56049-56059 (2015).

47. Kumar, D., Jain, V. \& Rai, B. Imidazole derivatives as corrosion inhibitors for copper: A DFT and reactive force field study. Corros. Sci. 171, 108724 (2020).

48. Barim, E. \& Akman, F. Synthesis, characterization and spectroscopic investigation of N-(2acetylbenzofuran-3-yl)acrylamide monomer: molecular structure, HOMO- LUMO study, TD-DFT and MEP analysis. J. Mol. Struct. 1195, 506-513 (2019).

49. Zhao, G., Zhong, H., Qiu, X., Wang, S., Gao, Y., Dai, Z., Huang, J. \& Liu. G. The DFT study of cyclohexyl hydroxamic acid as a collector in scheelite flotation. Miner. Eng. 49, 54-60 (2013).

50. Barim, E. \& Akman, F. Synthesis, characterization and spectroscopic investigation of N-(2acetylbenzofuran-3-yl)acrylamide monomer: molecular structure, HOMO- LUMO study, TD-DFT and MEP analysis. J. Mol. Struct. 1195, 506-513 (2019).

\section{Materials And Methods}




\section{Samples and reagents}

The quartz and magnetite single minerals used in the micro-flotation tests were form Alibaba co., Ltd. As seen in Supplementary Figs. 2a and b, the X-Ray Powder Diffraction (XRD) analysis results of the two samples showed that they have high purity and can be used for pure mineral flotation experiment. The magnetite ore for bench-scale flotation tests was the magnetite concentrate after magnetic separation and purchased from Daye Plant, Hubei Province (China). The mineral phase analysis results are including $52.98 \%$ magnetite, $25.88 \%$ quartz, $6.24 \%$ hornblende, $4.03 \%$ chlorite, $2.36 \%$ siderite, $0.84 \%$ hematite, $3.62 \%$ plagioclase, $1.55 \%$ potash feldspar, $2.50 \%$ ankerite and the chemical component was shown in Supplementary Table 1.

The novel trisiloxane collector, $\mathrm{N}$-( $\beta$-aminoethyl)- $\gamma$-aminopropyltrisiloxane (AAT), was prepared and purified in this laboratory. Because the solvents and agents used in the synthesis were analytical grade, they were used directly without further purification. Hydrogen-1 and carbon-13 nuclear magnetic resonance (NMR) spectra were gathered by Bruker Avance 400 spectrometer (Switzerland) in DMSO-d6 solvent to reveal the structure of AAT. The chemical molecular structures of the trisiloxane collector AAT and conventional collector DA were exhibited in Fig. 2 b.

\section{Micro-flotation tests}

The single mineral flotation experiments were carried out using $\mathrm{XFG}_{\|}$hanging cell flotation machine with specifications of $5-35$ g. 2.0 g pure magnetite or quartz was mixed with $30 \mathrm{~mL}$ deionized water as raw ore. First, hydrochloric acid and sodium hydroxide solutions were used to adjust the pulp pH (2-12). Then, AAT or DA was added to interact with minerals for 2 min. Finally, the manual blister operation lasted for 4 min (Supplementary Video 1). After flotation, the concentrate was dried and weighed to calculate the yield (yield=recovery). Each experiment was needed to be repeated three times, and the average was taken as the final result, and the error bars in the corresponding graph represented the standard deviation. The flow diagram of pure magnetite and quartz was shown in Supplementary Figs. 2c.

\section{Bench-scale flotation tests}

The experiments were carried using a $1.5 \mathrm{~L}$ XFD mechanical flotation cell. A mixture of $500 \mathrm{~g}$ magnetite ore and $0.8 \mathrm{~L}$ tap-water was placed in the flotation cell and full mixed to form a uniform pulp. AAT or DA was added into the slurry as a collector and stirred for $2 \mathrm{~min}$ to ensure full interaction between the reagent and the minerals. The operation of air inflation and bubble scraping in the rougher stage were carried out for $4 \mathrm{~min}$. Finally, the $\mathrm{TFe}$ and $\mathrm{SiO}_{2}$ grade was obtained by testing the magnetite concentrate, and the $\mathrm{TFe}$ and $\mathrm{SiO}_{2}$ recovery was calculated. The specific flotation process and parameters were displayed in Supplementary Figs. 2d.

\section{Contact angle measurement}


The contact angle of water droplets on the surfaces of magnetite and quartz was measured with Kruss DSA100 contact angle analyzer (Bruker, Germany) by the fixed drop method. The large samples of magnetite and quartz are polished to be smooth and cleaned with ethanol for contact angle measurement. For each measurement, the magnetite/quartz sample was immersed in $30 \mathrm{~mL}$ of the AAT/DA solution of the designed concentration. After being soaked for 15-20 min, the samples were fetched out and dried naturally. The final result was the average of three repeated tests.

\section{FTIR spectroscopy analysis}

The infrared spectrum of magnetite and quartz with and without AAT collector were recorded by a Nicolet iS 50 spectrometer on the $\mathrm{KBr}$ disk. At pH 7 and $25^{\circ} \mathrm{C}, 2.0 \mathrm{~g}$ of magnetite/quartz samples (below $5 \mu \mathrm{m}$ ) was mixed with $30 \mathrm{~mL}$ of aqueous solution with or without $5.0 \times 10^{-5} \mathrm{~mol} / \mathrm{L}$ AAT. After stirred for $2 \mathrm{~h}$, the mineral samples were filtered and dried for 2 days. The infrared absorption spectrum recorded on the $\mathrm{KBr}$ disk was from $500 \mathrm{~cm}^{-1}$ to $4,000 \mathrm{~cm}^{-1}$.

\section{Zeta potential measurement}

The zeta potential of magnetite and quartz was measured by a JS94H potential analyzer (Brookhaven, USA). The samples used for the measurement were ground with an agate mortar to below $5 \mu \mathrm{m}$. $0.01 \%$ magnetite/quartz particle suspension was prepared by pouring $0.02 \mathrm{~g}$ magnetite/quartz into $2,000 \mathrm{~mL}$ ionized water and stirring fully. In each measurement, under $0.1 \mathrm{~mol} / \mathrm{L} \mathrm{KNO}_{3}$ back-ground electrolyte, the suspensions with $5.0 \times 10^{-5} \mathrm{~mol} / \mathrm{L}$ AAT/DA and without collector were stirred for $10 \mathrm{~min}$, and then adjusted to a different $\mathrm{pH}$ value. The result obtained was the average of the three measured values.

\section{DFT calculation}

DFT calculation was studied by Gaussian $03^{51}$. The geometric structures and atomic charges of AAT and DA were calculated. The molecular structure models of trisiloxane AAT and DA are obtained through MM2 and PM3 methods. At the B3LYP/6-31G(d) level, the geometry was further optimized ${ }^{52,53}$.

\section{Economic estimation}

Economic estimation was made for a medium-sized magnetite concentrator with a processing capacity of 10,000 t/d and an annual workload of 330 days. The first step was to calculate the market price and the cost of the new agent AAT. In the second step, the increased profit was calculated based on the magnetite concentrate grade and the increased recovery.

\section{References}

51. Xu, B., Wu, J., Dong, Z., Jiang, T., Li, Q. \& Yang, Y. Flotation performance, structure-activity relationship and adsorption mechanism of a newly-synthesized collector for copper sulfide minerals in Gacun 
polymetallic ore. Appl. Surf. Sci. 551, 149420 (2021).

52. Yang, X., Liu, S., Liu, G. \& Zhong, H. A DFT study on the structure-reactivity relationship of aliphatic oxime derivatives as copper chelating agents and malachite flotation collectors. J. Ind. Eng. Chem. 46, 404-415 (2017).

53. Dong, Z., Jiang, T., Xu, B., Li, Q., Zhong, H. \& Yang, Y. Selective flotation of galena using a novel collector S-benzyl-N-ethoxycarbonyl thiocarbamate: An experimental and theoretical investigation. J. Mol. Liq. 330, 115643 (2021).

\section{Declarations}

\section{Acknowledgements}

The authors express their appreciation for the support of the Natural Science Foundation for Distinguished Young Scholars of Jiangxi province (Grant No. 20192BCB23016), Jiangxi Double Thousand Plan, the National Natural Science Foundation of China (Grant No. U1607108 and 51774152), Natural Science Foundation of Jiangxi, China (Grant No. 20181BAB216018 and 20171BCB18002), Educational Commission of Jiangxi Province of China (Grant No. GJJ170504), Program of Qingjiang Excellent Young Talents, Jiangxi University of Science and Technology.

\section{Author contributions}

Z.Q.H and V.Z.P designed the study and revised the manuscript. S.Y.Z and V.E.B performed the experiments and wrote the original manuscript. H.L.W, R.K.L and W.Y.L analyzed the results. C.C and S.Y.S synthesized and characterized the agent. X.Y.Y, G.C.H and W.F guided the experiments. All the authors contributed to the overall scientific interpretation and edited the manuscript.

\section{Competing interests}

The authors declare no competing interests.

\section{Additional information}

Supplementary information The online version contains supplementary material available.

\section{Figures}




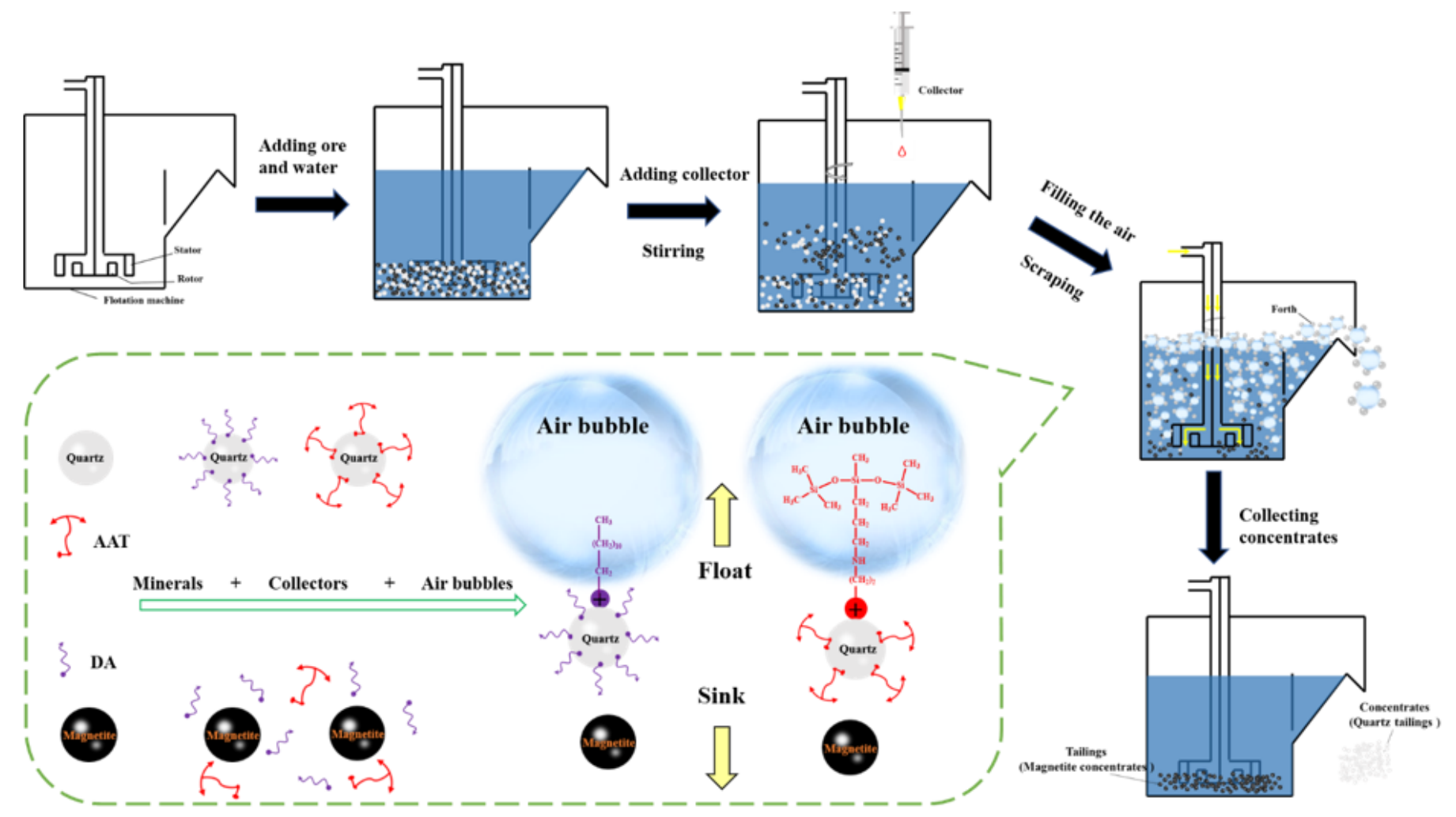

Figure 1

Schematic illustration showing a reverse flotation process of using a "parachute" structure trisiloxane surfactant AAT to enhance the effective separation of useful minerals and gangue minerals to realize efficient utilization of iron ore resources. AAT and DA have an oreophilic group and a lipophilic group. One end of the oreophilic group will be adsorbed on the mineral surface, and the other end of the lipophilic group extends into the air bubbles generated in the flotation machine, so as to form stable and hydrophobic mineral-froths. The trisiloxane surfactant AAT with a unique parachute structure has more excellent performance, stronger chemical activity and stability than the traditional alkyl surfactant DA, which significantly improves the reverse flotation effect of iron ore. 
a

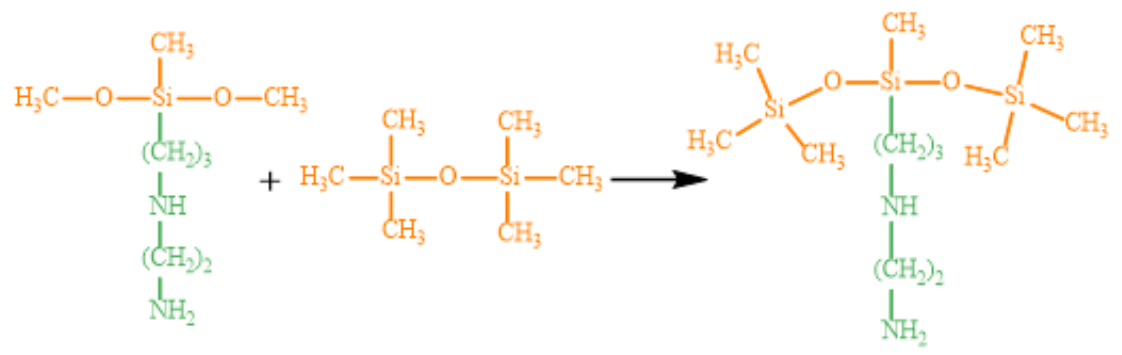

b

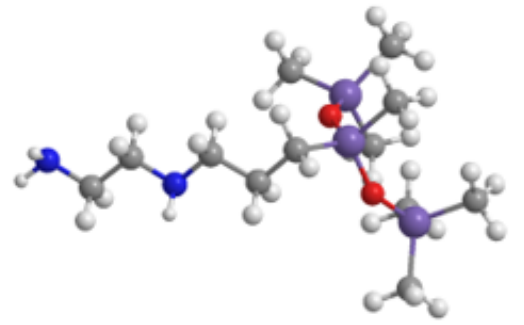

AAT

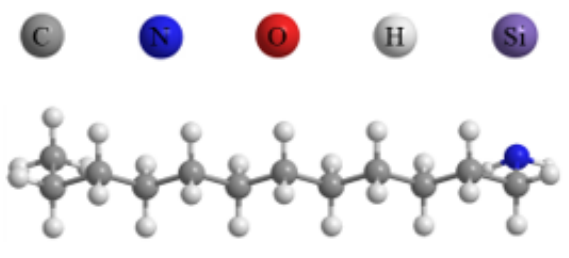

DA
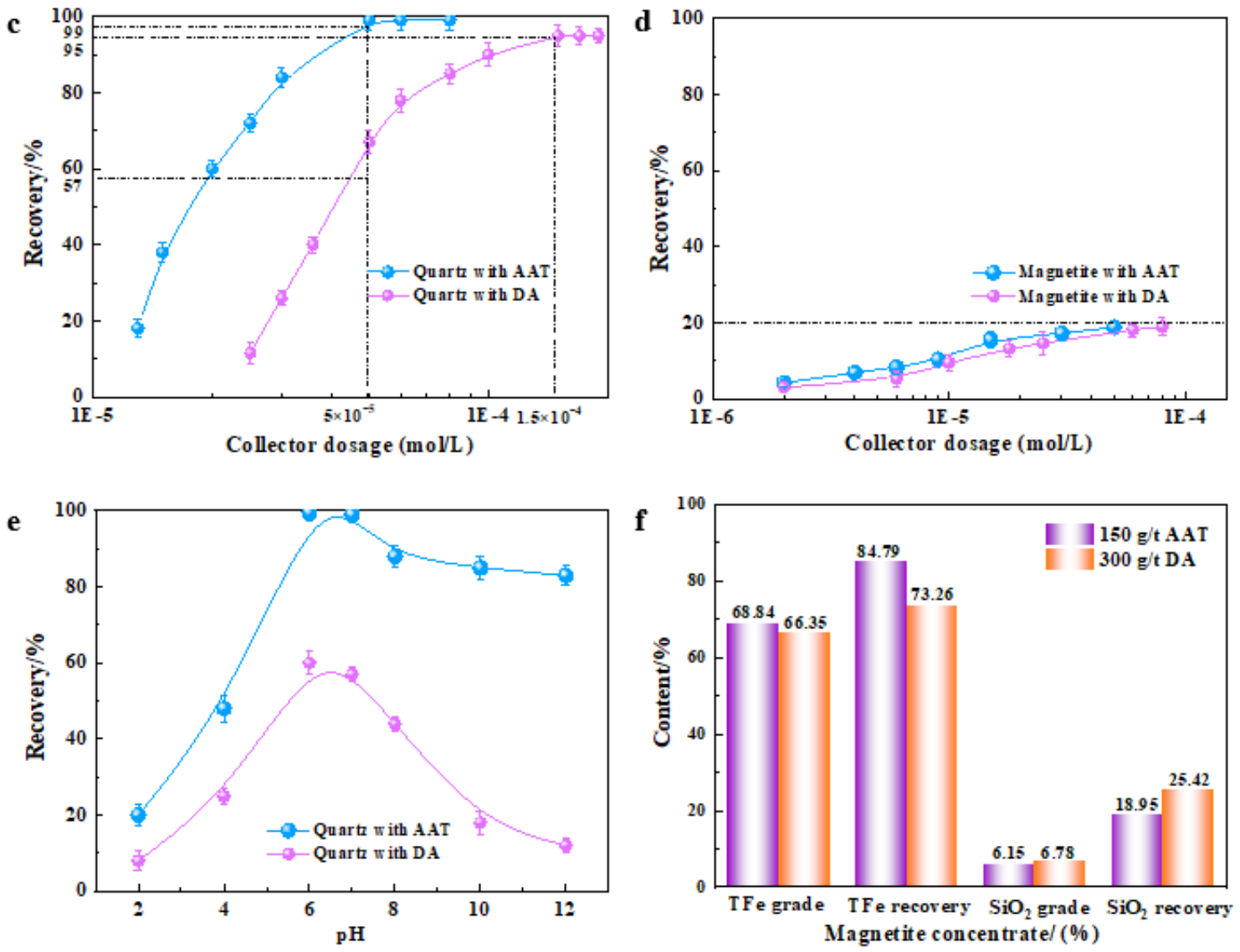

\section{Figure 2}

The synthesis route, molecular structure and flotation behavior of AAT. a, Synthetic route of AAT. b, The chemical molecular structures of AAT and DA. $\mathbf{c}$ and d, Effect of collector dosage on flotation recovery of quartz and magnetite at $\mathrm{pH} 7$. e, Effect of $\mathrm{pH}$ on flotation recovery of quartz using $5 \times 10^{-5} \mathrm{~mol} / \mathrm{L}$ collector. f, TFe and $\mathrm{SiO}_{2}$ grade and recovery in magnetite concentrate obtained by AAT and DA. 
a

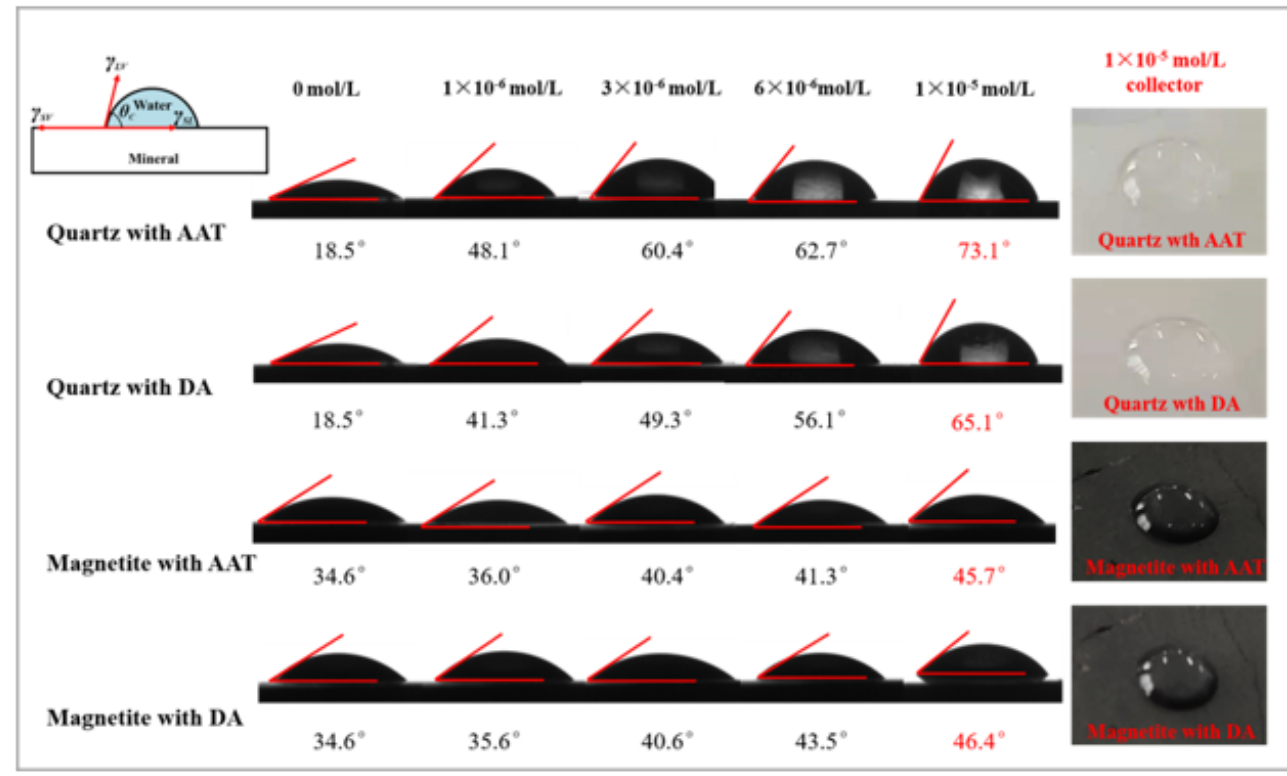

b

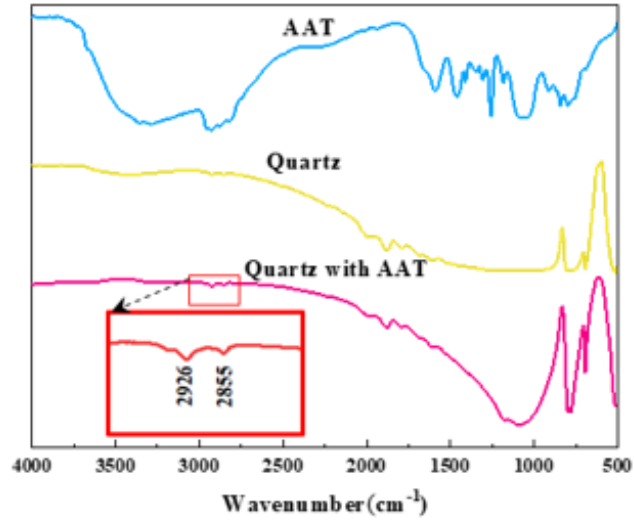

d

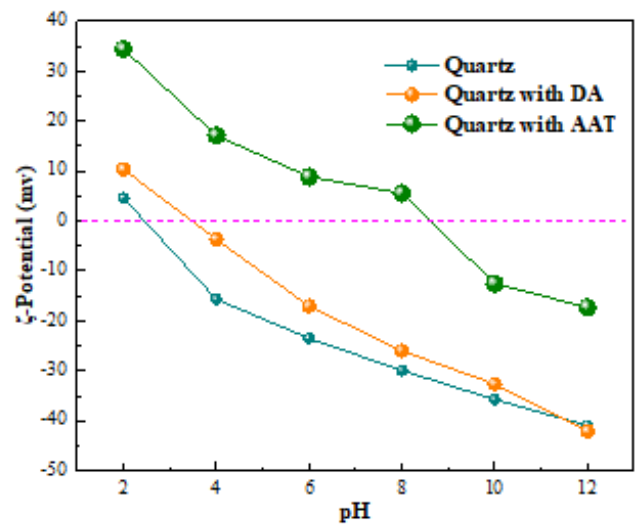

c
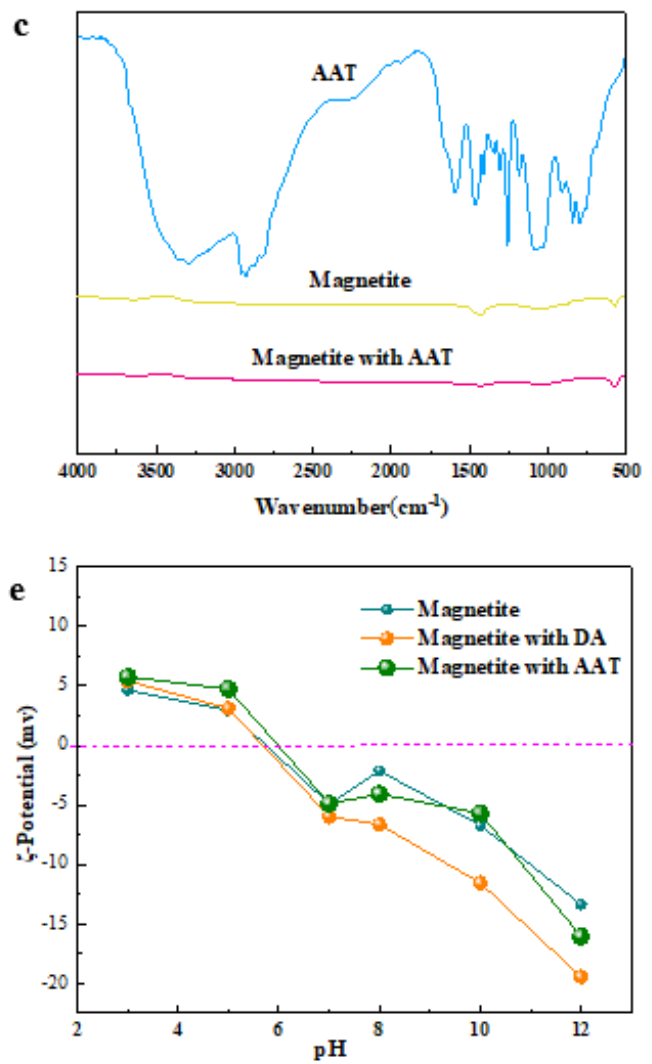

\section{Figure 3}

The adsorption mechanism of quartz and magnetite by AAT. a, The water contact angles of quartz and magnetite at different AAT and DA concentrations. $\mathbf{b}$ and $\mathbf{c}$, Infrared spectrum of quartz and magnetite before and after treatment with AAT. $\mathbf{d}$ and $\mathbf{e}$, The zeta-potential of quartz and magnetite with and without AAT collector interaction. 
a

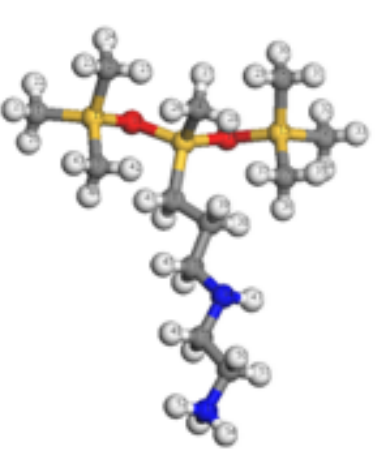

ANT

b

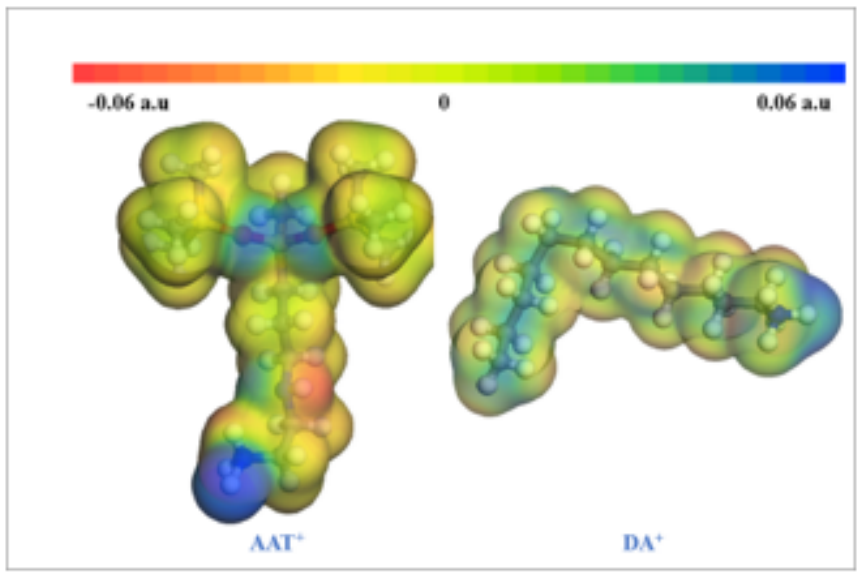

c

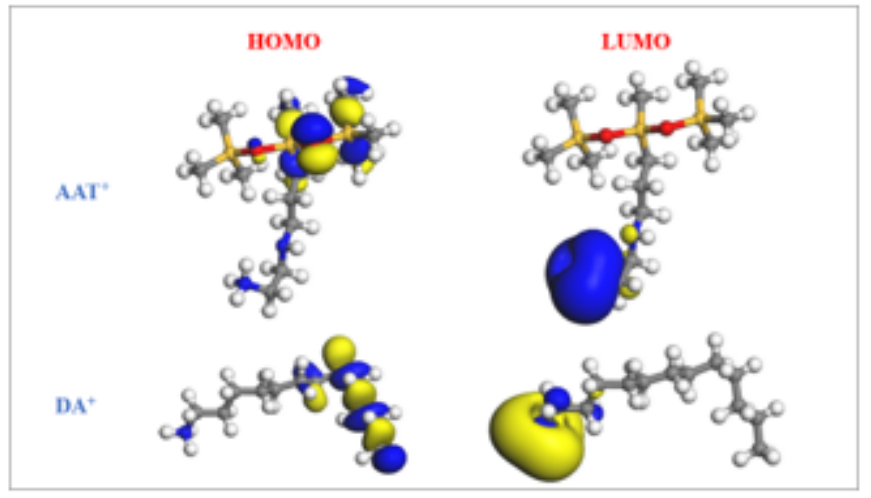

Figure 4

DFT calculation of AAT and DA. a, The optimized geometric structures of the $\mathrm{AAT}^{+}$and $\mathrm{DA} \mathrm{A}^{+} . \mathbf{b}, \mathrm{MEP}$ maps for $\mathrm{AAT}^{+}$and $\mathrm{DA}^{+}$molecule. c, Maps of HOMO and LUMO for $\mathrm{AAT}^{+}$and $\mathrm{DA}^{+}$.

\section{Supplementary Files}

This is a list of supplementary files associated with this preprint. Click to download.

- SupplementaryVideo1.mp4

- SupplementaryMaterial.docx 